\title{
A DIVISÃO ENTRE TRABALHO, FAMÍLIA E ORGANIZAÇÕES PARA CASAIS DE DUPLA JORNADA (TWO-JOB COUPLES): Notas para um Debate sobre o Caso Brasileiro
}

\section{THE DIVISION OF WORK, FAMILY AND ORGANIZATIONS FOR TWO- JOB COUPLES: Notes for a Debate on the Brazilian Case}

\author{
Diana Rebelo Neves \\ Unigranrio \\ dianarebello@hotmail.com
}

Rejane Prevot Nascimento

Unigranrio

rejaneprevot@uol.com.br

Submissão: $16 / 07 / 2017$

Aprovação: 23/11/2017

\begin{abstract}
RESUMO
O objetivo deste artigo é abordar a relação entre a jornada de trabalho diária e as tarefas domésticas entre os casais de dupla jornada (two-job couples), termo que define situações em que ambos os cônjuges mantém um vinculo de trabalho formal com organizações. Este tema, ainda pouco explorado nos estudos sobre trabalho no Brasil, será desenvolvido por meio de um ensaio teórico baseado, principalmente, no trabalho da socióloga americana Arlie Russell Hochschild, que estuda a temática do trabalho feminino e da dupla jornada há mais de 20 anos, além de abordar temas como família, cultura de mercado, padrões globais de cuidados de trabalho, psicologia social e a relação entre cultura e emoção. Outros autores ajudarão a complementar a discussão, cujo objetivo final é proporcionar um debate sobre esta temática considerando o contexto brasileiro.
\end{abstract}

Palavras-chave: Casais de Dupla Jornada. Trabalho Feminino. Trabalho Doméstico. 


\section{ABSTRACT}

The purpose of this article is to discuss the relationship between daily work and domestic chores between two-job couples, a term that defines situations in which both spouses maintain a formal working relationship with organizations. This subject, still little explored in the studies on work in Brazil, will be developed through a theoretical essay based mainly on the work of American sociologist Arlie Russell Hochschild, who studies the theme of women's work and the double journey for more than 20 years, In addition to addressing topics such as family, market culture, global patterns of work care, social psychology and the relationship between culture and emotion. Other authors will help to complement the discussion, whose final objective is to provide a debate on this theme considering the Brazilian context.

Keywords: Two-Job Couples. Female Work. Housework.

\section{INTRODUÇÃO}

No Brasil, nos últimos vinte anos, tem se acentuado o fenômeno da inserção da mulher no mercado de trabalho. Dados do IBGE demonstram que, em 2011, as mulheres eram maioria na população de 10 anos ou mais de idade (PIA), cerca de 53,7\%. Contudo, eram minoria $(45,4 \%)$ na população ocupada (PO). Essa estrutura distributiva reflete-se no nível de ocupação, relação que mostra o contingente de ocupados em relação ao total da PIA. Para as mulheres, esse indicador foi de 40,5\% em 2003 passando para 45,3\% em 2011. Na comparação com 2003, o crescimento da participação das mulheres na população economicamente ativa (PEA) foi de 1,8 ponto percentual (de $44,4 \%$ para $46,1 \%$ ). No mesmo período, a proporção de mulheres na população desocupada e na população ocupada teve elevação de, respectivamente, 3,3 e 2,4 pontos percentuais (IBGE, 2012).

Dessa forma, nota-se uma fuga do estereótipo que caracterizava a mulher brasileira até os anos setenta: o de dona de casa ou do lar. No cenário atual, grande parte das mulheres brasileiras, casadas ou não, dividem-se entre o trabalho fora de casa e o trabalho doméstico. Esta é, hoje, a realidade de muitos casais brasileiros, que se dividem entre as jornadas de trabalho cada vez mais extensas, metas corporativas, o cuidado com os filhos e o trabalho doméstico.

Como consequência desta realidade, verifica-se um progressivo adiamento, pelos jovens trabalhadores das classes médias urbanas brasileiras, do casamento e da paternidade/maternidade. As demandas do trabalho, a instabilidade na carreira e as jornadas sem horário fixo são algumas razões que levam a esse adiamento. Umas das constatações de Neves (2013) em sua pesquisa com jovens trabalhadores de grandes corporações brasileiras foi de que boa parte dos entrevistados encaravam a extensão da jornada de trabalho como um momento da vida profissional. Para essas pessoas, o fato de trabalharem por longas horas era encarado como uma fase da carreira em que precisavam se dedicar mais para obterem o crescimento e o sucesso profissional. Dessa forma, acreditavam que após o casamento e a chegada dos filhos iriam diminuir o ritmo e vivenciariam uma realidade de trabalho menos intensa, permanecendo menos horas nas organizações e dedicando-se mais à vida pessoal do que à vida profissional (NEVES, 2013).

Não obstante sua importância para a compreensão das transformações pelas quais o trabalho tem passado, a divisão entre o trabalho corporativo e o trabalho doméstico pouco tem sido estudada no Brasil. Também não se verifica um esforço das organizações brasileiras em se adaptarem às condições impostas pela formação e crescimento das famílias. As necessidades como o acompanhamento dos filhos à escola, às consultas médicas e às reuniões 
escolares são, por vezes, proibidas, de forma velada ou não pelas empresas, durante a jornada de trabalho.

Nos Estados Unidos, onde a inserção da mulher no mercado de trabalho ocorreu mais cedo do que no Brasil, o fenômeno denominado como second shift (segunda jornada) foi amplamente estudado na década de noventa por Hochschild (2012a). Segundo a autora, em 1975, apenas 39\% das mulheres com filhos menores de seis anos estavam na força de trabalho. Por volta de 2009, esse número havia subido para 64\%. Em 1975, 34\% das mães de crianças com menos de três anos estavam no mercado de trabalho; em 2009, esse percentual já era de $61 \%$. O mesmo ocorreu com as mães de crianças com um ano ou menos: $31 \%$ em 1975 e 50\% em 2009. O que se percebe é que, cada vez mais, mães de filhos pequenos estão inseridas no mercado de trabalho, fazendo surgir os chamados two-job couple (casais de dupla jornada) e acarretando uma série de consequências para a vida familiar e doméstica (HOCHSCHILD, 2012a).

Arlie Russell Hochschild é socióloga, professora emérita da Universidade da Califórnia, em Berkeley, que estuda temas como família, cultura de mercado, padrões globais de cuidados de trabalho, psicologia social e a relação entre cultura e emoção. A autora foi pioneira no campo de estudo conhecido como sociologia das emoções, campo este que discute as noções culturais de gênero no trabalho. Em seus estudos, a autora conclui, entre outras questões, que o influxo das mulheres na economia não foi acompanhado por uma adaptação das demandas do casamento e do trabalho, fazendo com que essa transição gere no casal uma grande sobrecarga (HOCHSCHILD, 2012a).

Apesar de estudar o fenômeno da inserção da mulher no mercado de trabalho e seus desdobramentos sobre as tarefas domésticas e a organização familiar desde a década de 90, os estudos de Hochschild são pouco conhecidos no Brasil (BONELLI, 2003). Com poucos trabalhos traduzidos para o português, a autora, apesar de tratar de um tema bastante atual e que encontra grande respaldo em estudos acadêmicos, é pouco conhecida e pouco estudada nas universidades brasileiras.

No Brasil, Heliani Berlato dos Santos vem estudando o fenômeno dos casais de dupla jornada - denominados como dual career. Em sua tese de Doutorado, que teve como objetivo explorar o fenômeno da dual career no Brasil e identificar os fatores associados a ele, Santos (2011) conclui que os casais de dupla carreira gastam mais tempo com o trabalho do que com as tarefas domésticas. Santos e Casado (2011a) destacam que, no Brasil, não existem trabalhos empíricos que tratem o tema dual career sob as óticas individual e organizacional.

Neste sentido, o objetivo deste artigo é abordar a relação entre a divisão das tarefas domésticas e o cuidado com os filhos entre os casais de dupla jornada (two-job couples), ou seja, em que ambos os parceiros trabalham no mercado corporativo. Para tanto, este trabalho basear-se-á em uma revisão teórica de autores que tratam deste tema, principalmente nos trabalhos da socióloga A. R. Hochschild. Casais em que ambos os cônjuges trabalham sentem o peso da demanda no cuidado com os filhos e com as tarefas domésticas, já que sobra menos tempo para se dedicarem às atividades do lar, fazendo com que dependam cada vez mais de uma ajuda externa e, muitas vezes, sejam obrigados a negligenciar alguns cuidados com os filhos.

Este trabalho está organizado em mais cinco seções, além desta Introdução e das considerações finais, onde são apresentadas as temáticas relevantes para esta discussão, a saber, as consequências da inserção das mulheres no mercado de trabalho; o contexto dos casais de dupla jornada e a divisão do trabalho doméstico; a terceirização da vida pessoal; e, o papel das organizações. 


\title{
2 A INSERÇÃO DAS MULHERES NO MERCADO DE TRABALHO
}

Sobre a inserção das mulheres no mercado de trabalho, Loureiro, Costa e Freitas (2012, p. 131) destacam que "um dos fenômenos mais significativos no mundo contemporâneo é a diversificação da mão de obra, com a entrada maciça das mulheres no mercado de trabalho". Hochschild (2012a) afirma que o número de mulheres no trabalho remunerado tem aumentado constantemente desde antes da virada do século, nos Estados Unidos, mas a partir de 1950 o aumento foi impressionante. Em 1950, 30\% das mulheres norte-americanas estavam na força de trabalho; em 2011 esse número subiu para 59\%. Mais de dois terços das mães, casadas ou solteiras, passaram a trabalhar; na verdade, mais mães do que não-mães trabalham. As mulheres passaram a representar metade da força de trabalho e os casamentos em que homens e mulheres trabalham representam até dois terços de todos os casamentos com crianças.

Considerando a realidade brasileira, Fleck e Wagner (2003) destacam a relevância de se considerar a entrada das mulheres no mercado de trabalho como um marco, principalmente em função do crescimento, nos últimos anos, "do número de lares brasileiros em que o trabalho feminino passa a representar a principal fonte de sustento econômico da família" (2003, p. 32). É importante, ainda, "considerar como as transformações sociais contemporâneas e os novos arranjos familiares atingem a estrutura e os padrões de funcionamento familiar, a partir da inserção da mulher no âmbito profisssional" (FLECK; WAGNER, 2003, p. 32).

Neste sentido, Oliveira (2009) aborda a constituição de novas configurações familiares na sociedade contemporânea em decorrência, segundo a autora, das transformações provocadas pela industrialização, pela urbanização e pela reorganização da população, que alteraram as feições familiares e sociais. Ainda, segundo Oliveira (2009):

\begin{abstract}
existe uma radical mudança na composição familiar, nas relações de parentesco e na representação de tais relações na família. Tal representação tem seu fundamento direto na transformação da configuração familiar e também nas relações sociais, ocasionando impacto profundo na construção da identidade de cada componente no interior da família. Essa construção da identidade irá rebater nas relações sociais ampliadas, não somente no seio familiar. Nesse contexto encontramos a 'nova família', que se caracteriza pelas diferentes formas de organização, relação e em um cotidiano marcado pela busca do novo. (OLIVEIRA, 2009, p. 67).
\end{abstract}

Essa nova família pode ter combinações de diversas naturezas, como por exemplo, "uniões de parceiros separados ou divorciados; uniões de pessoas do mesmo sexo; uniões de pessoas com filhos de outros casamentos; mães sozinhas com seus filhos, sendo cada um de um pai diferente; pais sozinhos com seus filhos; avós com os netos, entre outros" (OLIVEIRA, 2009, p. 68). Em função disso, são observadas algumas consequências dessas mudanças nas relações de parentesco no interior da família:

Cada vez mais são encontradas famílias cujos papéis estão confusos e difusos se relacionados com os modelos tradicionais, cujos papéis eram rigidamente definidos. As relações, comparadas com as estabelecidas no modelo tradicional, estão modificadas, os próprios membros integrantes da nova família estão diferenciados, a composição não é mais a tradicional, as pessoas também estão em processo de transformação, no sentido da forma de pensar, nos questionamentos, na maneira de viver nesse mundo em processo de mudança. (OLIVEIRA, 2009, p. 68).

Ainda sobre as transformações nas configurações familiares, Souza, Beleza e Andrade (2012) destacam algumas mudanças ocorridas nas funções da família, como o fato de ela não 
ser mais unidade reprodutiva; a maior autonomia e a individualização feminina, o que fragiliza o poder patriarcal; e o fato de sexo, conjugalidade e procriação não estarem mais necessariamente juntos. Essa reorganização familiar tem como característica a "união afetiva dos cônjuges (com ou sem filhos) que se unem não mais por uma vida inteira, mas por um período aleatório que, como em mais de um terço dos casos, termina em separação" (SOUZA; BELEZA; ANDRADE, 2012, p. 110). A partir dessas transformações na sociedade:

a informalidade nas relações conjugais foi se mostrando cada vez mais presente, como o crescimento do número de divórcios, a diminuição dos índices de casamento formal, a redução do número de filhos e do desejo das mulheres de tê-los. Estes elementos aparecem como aspectos significativos $\mathrm{e}$ favorecem as novas configurações familiares na contemporaneidade. (SOUZA; BELEZA; ANDRADE, 2012, p. 110).

A Revista Isto É publicou, em edição de 19 de outubro de 2012, uma matéria com dados que mostram que a sociedade brasileira está se organizando de forma muito parecida com a europeia e a norte-americana. $\mathrm{O}$ número de pessoas que vivem sozinhas aumentou, assim como os registros civis de casamentos homoafetivos, os divórcios, as mulheres chefes de família, além da queda intensa na fecundidade, fenômeno observado em todas as regiões brasileiras, independentemente de raça ou nível econômico. A matéria mostra ainda que as formas diferentes de organizar a casa e a família também estão ligadas à maior participação da mulher no mercado de trabalho. Mulheres no comando dos lares já são 32,2\%, contra 22,2\% dez anos antes. Além disso, as despesas da casa agora são compartilhadas entre os moradores em 34,5\% dos domicílios e aumenta o número de casais sem filhos. Fora do casal tradicional, as mulheres são maioria em vários critérios: na criação de filhos sem parceiro, na opção de morar só e no número de relacionamentos homoafetivos (53,8\%). (MENEZES, 2012).

Ao analisarem os conflitos entre trabalho e família vivenciados pelas mulheres, Bandeira et al. (2017) buscam compreender o empreendedorismo feminino como uma alternativa às mulheres que buscam conciliar melhor as demandas do trabalho e família, principalmente aquelas com filhos pequenos. Entretanto, por serem donas do negócio, as mulheres se envolvem bastante e acabam dedicando quase metade do seu dia ao empreendimento, em média onze horas, pois querem estar fisicamente presentes. Com isso, às vezes, percebem que a flexibilidade é confundida com a disponibilidade de tempo, o que acaba ocasionando a sobrecarga, pois além da excessiva dedicação ao trabalho estão sempre conectadas com as atividades laborais e não desligam nunca. Além disso, por priorizarem o trabalho e a família, dedicam pouco tempo a si (BANDEIRA et al., 2017).

Mesmo com todo o crescimento da participação da mulher no mercado de trabalho nos últimos anos e a ocupação de melhores postos de trabalho por elas, incluindo as transformações no papel e na posição da mulher na sociedade brasileira, é preciso não superestimar a profundidade dessas mudanças (ROCHA-COUTINHO, 2004). Para a autora, as desigualdades entre homens e mulheres nas empresas permanecem, sejam elas públicas ou privadas:

na prática, o que se pode observar é que o discurso social mudou muito pouco a sua definição de mulher, apesar de ter incorporado este novo papel - o de profissional interessada e competente - à identidade feminina e de ter, até certo ponto, questionado a doutrina da maternidade como essência. Isto é, ele continua a atribuir à mulher todos os encargos com a casa e a família, tributário ainda a características que, no fundo, a sociedade considera até agora como essencialmente femininas. Ou seja, na verdade, a identidade feminina não foi substancialmente alterada, mas sim ampliada para incluir este novo papel da mulher. (ROCHA-COUTINHO, 2004, p. 5) 
Sobre o tema, Nascimento (2017) entende que, mesmo com a crescente participação da mulher no mercado de trabalho e sua ascendência profissional aos cargos estratégicos das organizações, a elas ainda são impostas a escolha entre o trabalho e a família. Para analisar essa questão, a autora escreveu um artigo com o objetivo de compreender as concepções de maternidade das mulheres e mães executivas e seus respectivos desdobramentos em relação ao significado da maternidade e da parentalidade. A autora acredita que toda a discussão em torno da maternidade sugere que um novo modelo de família está surgindo, como mostram os trabalhos anteriormente citados, e que este afetará o ambiente organizacional (NASCIMENTO, 2017).

Rocha-Coutinho (2004) chama a atenção para o fato de que a identidade feminina sofreu alteração com a entrada da mulher no mercado de trabalho, incluindo um novo papel: o de profissional com uma carreira a ser desenvolvida, mostrando que a mulher não está limitada ao papel de esposa e mãe. Hochschild (2012a) entende que as mulheres estão estabelecendo uma nova base de poder e identidade. Se anteriormente as mulheres baseavam seu poder na atratividade para os homens ou na influência sobre os filhos, agora elas se baseiam mais nos salários ou na autoridade que exercem em seus trabalhos.

Sobre o tema, Lehner (2012) entende que as mulheres enxergam o trabalho como uma fonte primordial de identidade, ajudando a formar a essência delas. O trabalho passa a assumir um lugar central em suas vidas, sendo visto como seu primeiro projeto como pessoa. Muitas das mulheres entrevistadas pelas autoras afirmaram que não poderiam viver sem trabalhar, sendo esta atividade vista como indispensável em suas vidas. A inserção das mulheres no mercado de trabalho, assim como a mudança nas configurações na família introduzem o fenômeno objeto deste ensaio, que é a divisão, entre os casais de dupla jornada, das atividades domésticas e laborais, conforme será abordado na próxima seção.

\section{CASAIS DE DUPLA JORNADA (TWO-JOB COUPLES)}

O tema casais de dupla carreira vem sendo estudado há quase 50 anos e, por ser um fenômeno que cresce cada vez mais, merece ser alvo de novos estudos que tragam olhares ainda não explorados na academia (SANTOS, 2011). Segundo Santos e Casado (2011b, p. 14) é importante "refletir sobre a necessidade de se conhecer e entender o impacto do tema dupla carreira dentro da sociedade contemporânea, tendo em vista o aumento do número de casais que buscam esse estilo de vida".

Existem, na literatura, muitos termos para se definir a situação em que ambos os cônjuges estão inseridos no mercado de trabalho. Segundo Perlin e Diniz (2005), o casamento em que ambos os cônjuges trabalham fora em tempo integral é definido como de duplo trabalho ou de dupla carreira. Hochschild (2012a) refere-se a esses casais com o termo twojob couples, conforme descrito na Introdução desse trabalho. Smith (2011) utiliza o conceito de dual-earner couples (casais duplo-assalariados) para definir esses casais. Em sua tese de Doutorado, Santos (2011) utiliza o termo dual career para definir casais que, segundo a autora, têm como essência o fato de que homens e mulheres desenvolvem suas carreiras em conjunto, sendo que ambos assumem as responsabilidades pelas tarefas domésticas e os cuidados com os filhos paralelamente às suas carreiras profissionais. O termo foi criado há várias décadas por Rapoport e Rapoport citados por Santos (2011, p.1).

Santos e Casado (2011a, p. 14) destacam que "o fenômeno de dupla carreira vem aumentando gradativamente e, com isso, várias mudanças no contexto social e econômico são percebidas". Ainda segundo as autoras, novos conceitos vêm surgindo para caracterizar a relação entre casais em que ambos os cônjuges trabalham fora sendo eles definidos "de acordo com as pretensões do casal". Também, segundo Santos (2013, p. 2), "o tema dual 
career, tendo quase meio século de vida, ainda incita descobertas, principalmente em razão de toda a metamorfose social, econômica, cultural e política que a sociedade vem vivenciando".

Santos (2012, p. 1) entende que a inserção da mulher no mercado de trabalho e o surgimento dos casais de dupla jornada alteraram "o modelo familiar tradicional e a identidade de homens e mulheres em relação ao desempenho de suas funções". Portanto, o desafio passa a ser encontrar estratégias que permitam conhecer o comportamento dessas famílias que optaram pela dupla carreira. Uma delas é identificar as principais prioridades dos casais, para entender quais são suas necessidades mais importantes no campo pessoal e organizacional, ou seja, definir o perfil desses casais para entender seu estilo de vida (SANTOS, 2015).

Um ponto importante levantado por Santos (2015) está no fato de que aspectos como carreira e família afetam diretamente esses casais, embora de maneira diferente para homens e mulheres. Essas diferenças podem ser mais facilmente percebidas nas reações dos mesmos à crises, expectativas e oportunidades de carreira ao longo da vida.

Santos (2013) chama a atenção para as consequências que a opção pela dupla carreira pode trazer para os casais, tema esse que será abordado mais profundamente na próxima seção. Segundo a autora, "a sobrecarga ou a incompatibilidade de funções entre os cônjuges são grandes geradoras de conflitos e interferem no campo pessoal e profissional do indivíduo" (SANTOS, 2013, p. 2). Segundo Santos e Casado (2011b):

a prática da dual career pelos casais está completamente imbuída de questões conflituosas sobre a relação trabalho-família, visto o 'universo' - individual e social - na qual está envolvida. (...) é relevante entender os conflitos que tais mudanças trazem em relação ao trabalho e a família (work-family conflict), a fim de compreender melhor os aspectos do indivíduo e da organização. (SANTOS; CASADO, 2011b, p. 14).

Madalozzo, Martins e Shiratori (2010) destacam que na década de 70 a participação das mulheres no mercado de trabalho ainda era bastante baixa, em torno de $18 \%$. Com o passar dos anos esse cenário foi sendo alterado:

Em 2002, a participação das mulheres no mercado de trabalho já atingia os $50 \%$, segundo dados do IBGE. Ao mesmo tempo, a diferença de salários entre homens e mulheres diminuiu drasticamente. No Brasil, ela passou de $50 \%$ no início da década de 90 para menos de $30 \%$ no início dos anos 2000. Na Europa, embora essa diferença seja bem inferior à verificada no Brasil, de aproximadamente $15 \%$, desde 2003, ela está estável. (MADALOZZO; MARTINS; SHIRATORI, 2010, p. 548).

Loureiro, Costa e Freitas (2012) destacam que:

no Brasil, as estatísticas apontam que a taxa de incorporação das mulheres ao mercado de trabalho é mais rápida que a dos homens e que as mulheres vêm ascendendo à cargos de direção nas organizações, apesar da existência reconhecida de fortes barreiras à essa ascensão. As possibilidades de construção de uma vida profissional bem-sucedida estão, naturalmente, condicionadas a exigências organizacionais específicas, mas também ao contexto mais amplo - econômico, institucional e cultural - do trabalho. (LOUREIRO; COSTA; FREITAS, 2012, p. 131).

Cramer et al. (2012) chamam a atenção para o fato de que a inserção da mulher no mercado de trabalho traz novos significados, por vezes mais complexos, para as organizações. Os autores acreditam que: 


\begin{abstract}
as relações de trabalho ganham novos significados e complexidades a partir da inserção feminina no espaço organizacional. A disputa acirrada no espaço de trabalho passa a ser vivida por homens e mulheres que buscam igualar suas oportunidades por cargos, posições hierárquicas, destaque e reconhecimento na profissão. No processo de construção de uma nova identidade, as mulheres procuram desconstruir estereótipos sociais e culturais há tempos construídos para que seja possível a transposição de barreiras, principalmente de natureza psicológica, que ainda permanecem e que se mostram como as mais difíceis de serem superadas. (CRAMER, et al., 2012, p. 54).
\end{abstract}

Não obstante esta crescente participação das mulheres no mundo corporativo, submetidas às mesmas pressões por resultados e alcance de metas, as pesquisas de Hochschild (2012a), Santos $(2013 ;$ 2011) e Nascimento (2017) revelam que a divisão do trabalho doméstico ainda não é equânime, estando as mulheres ainda responsáveis pelo maior volume de atividades que visam dar conta da organização e cuidado com os filhos e das tarefas que compõem a rotina diária das famílias.

\title{
4 A DIVISÃO DO TRABALHO ENTRE HOMENS E MULHERES EM CASA
}

Para Daniel (2011, p.339), “o ingresso da mulher no mercado de trabalho está diretamente relacionado à sua participação na vida familiar, exigindo que elas desenvolvam estratégias de conciliar família e trabalho". Madalozzo, Martins e Shiratori (2010) chamam atenção para o fato de que, mesmo com a mudança da mulher para o mercado de trabalho, dividindo com o homem o mercado profissional, as mulheres ainda mantêm o seu papel de dona de casa, sendo elas as responsáveis pelas tarefas domésticas.

O mesmo foi constatado na pesquisa de Hochschild (2012a). Na pesquisa desenvolvida para o livro The Second Shift, Hochschild entrevistou 50 casais, observando a vida doméstica de 12 destes entrevistados. Os casais pesquisados eram heterossexuais, com filhos abaixo de 6 anos de idade, ambos empregados em grandes empresas. De acordo com os casais pesquisados por Hochschild (2012a), o conflito mais difundido entre maridos e esposas parece ser sobre a participação dos homens dentro de casa. Nesse sentido, Diniz (1999) sugere que a falta de igualdade na divisão de tarefas domésticas, na administração da casa e na educação e cuidado dos filhos são fatores geradores de estresse na esfera familiar.

Segundo Hochschild (2012a), como muitas mulheres ingressaram no mercado de trabalho, as famílias foram atingidas por uma aceleração no trabalho e na vida familiar, e são principalmente as mulheres que absorvem essa aceleração. Mesmo quando os casais dividem mais equilibradamente as tarefas domésticas, as mulheres ainda são responsáveis por dois terços dos trabalhos diários em casa, como cozinhar e limpar - trabalhos estes que impõem a elas uma rotina rígida.

Além dos cuidados com a casa, as mulheres também estão mais comprometidas com o cuidado com os filhos. Venturiello (2012) verifica, em seu estudo, que as mulheres ocupam mais tempo que os homens nessa atividade. São elas que frequentemente adaptam sua vida profissional a esta tarefa, muitas vezes reduzindo as horas de trabalho para ter mais tempo com os filhos. São as mães que adaptam, na grande maioria das vezes, suas jornadas de trabalho para dar conta dos cuidados demandados pelos filhos. Ainda assim, mesmo que em menor grau, as rotinas de trabalho dos pais também têm sido modificadas.

Sobre o tema, Perlin e Diniz (2005) destacam, como resultado de seu estudo, o ônus desigual pago pelas mulheres que vivem a realidade de duplo trabalho. Para as autoras, as mulheres, enfrentam múltiplas jornadas de trabalho, já que são elas as responsáveis pela 
maioria das tarefas da casa e pelo cuidado com os filhos, o que acaba por gerar a alta insatisfação feminina com relação à divisão do trabalho doméstico.

Diante desse cenário, muitas mulheres acabam abrindo mão de suas próprias necessidades. Atividades como ler, assistir televisão, visitar amigos, fazer exercícios, ou mesmo ter tempo sozinha, passam a não existir na vida delas. Faz parte da cultura das mães que trabalham abrir mão de seu lazer (HOCHSCHILD, 2012a).

Hochschild (2012a) entende que, mesmo quando os homens dividem as horas de trabalho em casa, as esposas se sentem mais responsáveis pela casa e pelos cuidados com as crianças. As mães estão mais preocupadas do que os pais com as consultas no pediatra, são elas que, em geral, ligam para as babás quando estão no trabalho e ficam responsáveis pelas tarefas da escola e pelos aniversários infantis, dentre outras atividades.

Ao contrário de Hochschild, Lehner (2012), em seu trabalho sobre mulheres argentinas, revela uma mudança, ainda que pequena, no padrão de divisão de tarefas entre homens e mulheres dentro de casa. A autora ressalta que, ainda que não dividam igualmente as tarefas domésticas, os homens ficam responsáveis por muitas tarefas de cuidados com seus filhos, como dar banho, dar comida, brincar com eles. Para a autora, é possível notar que surgem novas identidades masculinas que qualificam o novo modelo de pai.

Outro aspecto que merece atenção é o conflito vivenciado pelas mulheres que, tendo que dividir sua atenção entre as responsabilidades do trabalho e da casa, se sentem sobrecarregadas e acabam questionando seu papel como mãe. Nesse sentido, Garey (2011) entende que as mães que trabalham sentem-se mais vulneráveis às críticas quanto a seu desempenho como mães porque o trabalho e a maternidade são retratados como se um diminuísse o outro. Assim, as mulheres utilizam várias estratégias para mostrar aos outros que são boas mães.

Diante do exposto, torna-se interessante destacar uma certa incoerência/discordância entre a prática e o discurso masculino e feminino, constatada por Perlin e Diniz (2005). Para as autoras:

\begin{abstract}
Ao mesmo tempo que ambos concordam com a necessidade de uma atitude igualitária, no dia-a-dia tendem a adotar uma postura tradicional (...) As mulheres tendem a colocar empecilhos na atuação doméstica dos homens. Talvez isso ocorra pela manutenção do mito social de 'rainha do lar', ou mesmo por receio ou culpa de perder o domínio de uma área da qual, durante muito tempo, foi a principal especialista. (PERLIN; DINIZ, 2005, p. 24 e 25).
\end{abstract}

Na mesma linha de pensamento está Venturiello (2012), posto que a autora acredita na existência de domínios masculinos e femininos no cuidado com os filhos. Ela constata ainda que boa parte das mulheres pesquisadas por ela acredita ser papel da mãe levar o filho ao médico. Para elas, são suas as responsabilidades por garantir as necessidades básicas dos filhos, como fome, sono, moradia, ir ao médico, aos aniversários. Diante dessa constatação, não surpreende que algumas mulheres manifestem dificuldade em delegar tarefas aos seus parceiros (VENTURIELLO, 2012). Da mesma forma, um estudo realizado por Fleck e Wagner (2003) revelou que:

a mulher ainda se sente responsável pelos cuidados com os filhos, necessitando conciliar, constantemente, as demandas das esferas pública e privada. Ao passo que o homem permitia-se buscar um espaço individual, não abdicando de seus momentos de lazer, a mulher sentia culpa e não se permitia abandonar, mesmo que temporariamente, seu papel predominantemente materno. (FLECK; WAGNER, 2003 , p. 37). 
A diferença desse novo modelo familiar, segundo Venturiello (2012), é que os homens mostram uma predisposição maior a dar atenção a seus filhos do que as gerações anteriores, que tinham o predomínio de um pai mais distante e provedor. As mães seguem encarregadas das tarefas referentes ao cuidado com a saúde e a educação dos filhos, enquanto os pais se tornam "uma presença mais lúdica que reforça o prazer de compartilhar momentos com os filhos" (VENTURIELLO, 2012, p. 79).

Ainda, assim, Champalbert (2012) reforça que, mesmo com a mudança no papel masculino dentro de casa, os homens que se veem satisfeitos com seus comportamentos como pais e que evoluíram quanto ao seu desempenho no universo doméstico, não escondem que as responsabilidades das tarefas continuam, majoritariamente, sob o domínio de suas esposas. Ainda segundo a autora:

Talvez a mudança mais importante consista no fato de que os homens admitem sem risco para sua masculinidade o conceito de que devem assumir parte do trabalho doméstico e nenhum deles usa como desculpa o trabalho externo ou termos econômicos para se esquivar destas tarefas. Mas, sem que reparem conscientemente, homens e mulheres submetem-se a papéis que a sociedade ainda mantém como femininos e masculinos, embora as funções originais e os âmbitos de desempenho venham variando notavelmente. (CHAMPALBERT, 2012, p. 91-92).

A sobrecarga de responsabilidades de trabalho corporativo com as atividades domésticas e cuidados com os filhos, aliadas à ausência de uma estrutura familiar que possibilite um suporte nas tarefas desenvolvidas pelas mulheres em casa, acarreta a dependência crescente de babás, empregadas, creches, colônias de férias, motorista e toda uma variada gama de serviços que têm por objetivo compartilhar com os casais, e em particular com as mães, os cuidados com a casa e os filhos. Este processo, definido por Hochschild (2005) como de terceirização da vida pessoal, pode ser entendido como a transferência de atividades que anteriormente estavam restritas à esfera privada, o cuidado de si e da família, para a esfera pública, dos serviços contratados. O contexto dessa transformação é que será abordado na seção seguinte.

\section{A TERCEIRIZAÇÃO DA VIDA PESSOAL}

Segundo Hochschild (2005), o termo terceirização sugere que situações que deveriam ocorrer dentro de casa estão acontecendo fora dela. O que a terceirização faz é importar imagens culturais de algum lugar de fora de casa para dentro dela: a responsabilidade pelas tarefas não está mais dentro de casa.

Contando com pouco ou nenhum suporte das famílias, das empresas e do governo para resolver a questão da falta de tempo em casa, as pessoas passaram a olhar para a única solução restante - o mercado. As famílias com condições financeiras contratam serviços para realização de tarefas do lar - como motoristas, governantas, babás, empregadas domésticas, amas de leite - terceirizando, assim, boa parte de suas vidas (HOCHSCHILD, 2012b). Quanto mais entranhado na vida pessoal o mercado está, mais as pessoas se convencem de que precisam dos serviços pagos para boa parte de suas necessidades íntimas (HOCHSCHILD, 2012b).

Durante a realização de uma pesquisa feita com trabalhadores de uma organização (Amerco) para o livro The Time Bind: When Work Becomes Home and Home Becomes Work, Hochschild (1997) concluiu que uma das estratégias utilizadas pelos pais que precisavam lidar com a falta de tempo para os filhos e para os cuidados com a casa foi reajustar suas ideias a respeito de como atender às necessidades da família. Ao invés de tentarem eles mesmos 
atenderem essas necessidades, eles pagavam outras pessoas para fazer isso por eles. Assim como acontece dentro de muitas empresas, eles terceirizaram partes cada vez maiores da rotina familiar.

Para Hochschild (1997), existem muitos substitutos para os serviços familiares colônia de férias para as crianças e casas de repouso para os idosos, por exemplo - que já se tornaram características aceitáveis da vida moderna. Segundo a autora, a nova indústria do tempo vende produtos e serviços prontos que poupam tempo, muitos dos quais são voltados para as mulheres que trabalham, especialmente do meio urbano e classes superiores.

Para a autora, as mães famintas por tempo estão sendo cada vez mais forçadas a escolher entre desempenharem elas mesmas seu papel de mães ou comprar uma cômoda versão de ser mãe de outra pessoa. Ao contar com uma variedade cada vez maior de produtos e serviços prontos para substituírem o que elas não podem suprir, as mães tornam-se cada vez mais gerentes da maternidade, e passam a coordenar as peças terceirizadas da vida familiar. Esta tendência para a mercantilização da vida doméstica parece estar ganhando cada vez mais reforço (HOCHSCHILD, 1997).

Segundo Hansen (2011), os pais constroem uma rede de relacionamentos porque eles precisam de ajuda. Em sua pesquisa com pais e mães que trabalham fora de casa, Venturiello (2012) constata justamente a necessidade de contar com a ajuda de empregadas domésticas, babás ou familiares. Segundo a autora, cada família resolve essa questão de acordo com sua situação financeira, sempre na tentativa de cobrir as horas que os filhos não estão na escola. Dessa forma:

as mães entrevistadas necessitam de uma rede de pessoas que protejam seus filhos, que podem ser as instituições (escolas e creches), as empregadas domésticas e os familiares. Muitas vezes, as mulheres optam por uma alternativa depois de pensar o que é melhor para seus filhos e que 'sistema' é mais eficiente. O caminho que constroem resulta da conjunção entre seus planos ideais, as possibilidades materiais e o cumprimento dos mediadores. (VENTURIELLO, 2012, p. 74).

Em contrapartida, muitos pais e mães de cargos médios não tinham dinheiro suficiente para contratar uma babá ou para matricular seus filhos em atividades extracurriculares após a escola. Por isso, alguns deixavam os filhos sozinhos em casa, o que gerava um sentimento de culpa maior nas mulheres do que nos homens que tomavam essa atitude. Outros, contavam com as mães, sogras ou outros membros da família para o cuidado com os filhos embora, em muitos casos, essas mulheres também trabalhassem (HOCHSCHILD, 2012a). Sobre essa questão, Venturiello (2012) destaca que:

Recorrer à ajuda de avós e avôs ou outros familiares também faz parte da rotina dos cuidados, embora prefiram não demandá-los (sic) constantemente. Um dos principais motivos para isso é que as mães e pais buscam resguardar o vínculo entre avós e netos, que acabaria desgastado se fossem seus cuidadores diários. No entanto, contam com eles para eventualidades como saídas dos pais e doenças dos filhos. Em vários casos os avós também trabalham, por isso não podem ser os cuidadores diários. (VENTURIELLO, 2012, p. 75).

Para Champalbert (2012), a situação doméstica dos casais de classe média inseridos na realidade de dupla carreira permanece em um delicado equilíbrio graças à terceirização dos serviços necessários para a manutenção da casa e dos cuidados com os filhos. Dessa forma, a presença das empregadas domésticas e babás - que são pagas para fazer as tarefas de casa que, por falta de tempo ou por cansaço, essas mulheres não podem fazer em sua totalidade garantem a paz dentro desses lares. 


\section{O PAPEL DAS EMPRESAS}

Hochschild (2012b), levanta um ponto de fundamental importância em torno desta discussão. A autora destaca que, apesar da inserção das mulheres no mercado de trabalho, a maioria das empresas e corporações se manteve inflexível em face das demandas familiares dos seus trabalhadores, e em casa, a maioria dos homens ainda tem de se adaptar às mudanças em função da ida da mulher para o mercado. Esta tensão entre a mudança das mulheres decorrente de sua inserção no mercado de trabalho e a ausência de mudanças em muitas outras esferas da vida corporativa leva a autora a tratar estas transformações como uma revolução estagnada.

Para Hochschild (1997), é necessário que exista um movimento que deve não só encorajar a empresa a oferecer políticas que permitam a redução ou a flexibilidade das horas trabalhadas, mas que também permita desafiar as premissas da atual cultura de trabalho. Questionamentos a respeito do desempenho dos funcionários e do tempo que se permanece dentro do local de trabalho devem ser feitos, para que se desvincule a produtividade do tempo dentro da empresa (HOCHSCHILD, 1997).

Algumas outras questões que devem ser levadas em consideração para a realização desse movimento são: quantas horas por dia, por semana, por ano, as pessoas devem trabalhar? Como é possível pressionar por melhores condições de trabalho sem torná-los refúgios da vida em casa? Como os pais podem alcançar um equilíbrio entre família e trabalho? Em uma época de crescente desigualdade de renda, como pode haver mais tempo disponível para os trabalhadores? Para a autora, os mais interessados em uma solução para essa questão são as crianças que passaram uma infância marcada por longas esperas de seus pais ausentes (HOCHSCHILD, 1997).

Muitas das reformas básicas necessárias para um movimento no tempo já foram testadas com sucesso e seus reflexos podem ser percebidos na cultura e no desenvolvimento social de alguns países. Países como a Noruega, Suécia e Alemanha desenvolveram alternativas criativas para administrar o tempo de trabalho de seus funcionários. Esses países têm mantido uma economia próspera durante décadas, com muitos setores da economia tendo uma semana de trabalho de 35 horas. Os trabalhadores suecos e alemães têm uma média de seis semanas de férias por ano; enquanto os holandeses têm cinco semanas. Em contraste, os norte-americanos têm apenas duas semanas e meia de férias por ano. O governo sueco subsidia creches, mantém elevados padrões de segurança e ambientes estimulantes nos centros de acolhimento de crianças em todo o país (HOCHSCHILD, 1997).

A autora acredita que um movimento de tempo não terá sucesso sem mudanças nas condições sociais contemporâneas. O poder crescente do capitalismo global, o declínio dos sindicatos de trabalho, e a erosão da sociedade civil, dentre outras questões, podem enfraquecer esse movimento, ou até mesmo impedir que ele aconteça. A escassez de trabalho pode fazer com que as pessoas trabalhem com medo, e por mais horas, mas também pode forçar as empresas e os sindicatos a olhar para maneiras de compartilhar mais postos de trabalho com menos horas (HOCHSCHILD, 1997).

Hochschild (1997) não oferece propriamente uma solução para a questão do alongamento da jornada de trabalho e todas as consequências geradas por essa necessidade de se trabalhar mais, mas ela sugere a necessidade de um movimento para reformular o tempo de trabalho. Para que esse movimento tenha sucesso são necessárias mudanças nas condições sociais contemporâneas.

Sobre o caso brasileiro, Nascimento (2017, p. 7) entende que "as famílias estão alterando suas ideologias culturais e sociais e isso afetará os modelos organizacionais vigentes, em que as atribuições dos funcionários estão fundamentadas nos papéis de gênero, 
do homem e da mulher". Para a autora, em um futuro próximo homens e mulheres vão se complementar no cuidado com a família e nas atividades profissionais. Portanto, há uma "discussão que precisa ser pensada e feita pelas organizações em relação ao tratamento de seus funcionários, pois será com base no contexto familiar contemporâneo que as transformações dessa relação irão acontecer" (NASCIMENTO, 2017, p. 7).

Vilela e Lourenço (2017) destacam a dificuldade existente em conciliar as demandas do trabalho e da família, o que tem contribuído para que homens e mulheres enfrentem conflitos entre essas duas esferas. Visando reduzir os impactos negativos causados por tais conflitos, as organizações e os governos de vários países têm proposto políticas para auxiliar na harmonia entre trabalho e família. Diante dessa realidade, as autoras escreveram um artigo cujo objetivo foi analisar como as políticas organizacionais e governamentais que visam reduzir o conflito trabalho-família se diferem entre países. As autoras concluíram, através da bibliografia utilizada como suporte em sua pesquisa, "que nem sempre as políticas organizacionais e governamentais atingem o fim a que se propõem. Isso acontece muitas vezes devido às expectativas presentes nas entrelinhas das organizações que inibem a utilização dos benefícios por partes dos membros" (VILELA; LOURENÇO, 2017, p. 7). As autoras concluem apontando a necessidade de se constituírem políticas públicas e programas no âmbito das organizações que visem à melhoria na qualidade de vida de seus funcionários, o que inclui uma maior adequação das demandas do trabalho à família e à vida pessoal.

\section{CONSIDERAÇÕES FINAIS}

Este trabalho teve como objetivo abordar a relação entre a divisão das tarefas domésticas e o cuidado com os filhos entre os casais de dupla jornada (two-job couples), a partir da literatura nacional e internacional sobre esta temática, que permitisse traçar algumas reflexões sobre o tema. A fim de subsidiar esta discussão, abordou-se não apenas estudos sobre a divisão das atividades doméstica e o cuidado dos filhos entre os casais, mas também as consequências desta sobrecarga sobre as famílias, acarretando o processo já discutido em seção anterior de terceirização da vida, e o papel das políticas organizacionais que possibilitassem minimizar esta situação.

Uma das questões sobre a qual se lança luz neste artigo diz respeito ao fato de que, embora exista uma maior participação dos homens nas tarefas domésticas e no cuidado com os filhos, ela ainda é muito inferior à feminina. Dessa forma, ao ingressar no mercado de trabalho as mulheres acabam por acumular funções, passando a trabalhar dobrado: um primeiro turno nas empresas, seguido por uma segunda jornada quando chegam em casa, já que são elas as principais responsáveis pela realização das atividades da casa e pelos cuidados com as crianças. Com esse excesso de atividades, as mulheres acabam questionando sua função como mães, não só pelo pouco tempo que sobra para cuidar e dar atenção aos filhos, mas também pela crítica e cobrança feita sociedade sobre as mulheres que trabalham fora como se elas não fossem mães em tempo integral. Num país ainda fortemente marcado pela visão do homem como o chefe da família e provedor, e com pouco espaço para o reconhecimento das necessidades femininas (mesmo quando as mulheres são também responsáveis pela renda doméstica, por vezes como renda principal), como no caso do Brasil, tal fato se torna ainda mais acentuado.

Além da questão da divisão entre maternidade/trabalho doméstico, verifica-se que consequências da pressão do trabalho sobre as mulheres são ainda mais significativas, mesmo quando estas ainda não têm filhos. $\mathrm{O}$ adiamento da maternidade tem levado mulheres a engravidarem em uma idade em que este processo já não é mais tão fácil, dada a queda de fertilidade que acompanha o envelhecimento feminino, em particular a partir dos 30 anos. 
Observa-se, neste contexto, um crescimento da procura por métodos de fertilização em clínicas especializadas e tratamentos caros que viabilizem a gravidez. Estes métodos, baseados em uma sobrecarga hormonal no organismo feminino, podem trazer, além da gravidez, consequências para a saúde da mulher.

Outra conclusão a que se chega é que as pessoas estão passando por profundas mudanças em suas vidas pessoais na contemporaneidade, em função da terceirização de partes importantes de suas necessidades íntimas. Com o tempo cada vez mais escasso, sobretudo devido a um trabalho com crescentes demandas, as pessoas voltam-se para o mercado. Muitos serviços oferecidos pelo mercado são responsáveis pela mercantilização da vida íntima, fato esse que vem tornando as relações cada vez mais despersonalizadas e vazias.

No caso brasileiro, diferentemente do que ocorre nos EUA e em países da Europa, a terceirização da vida privada já ocorre, historicamente, na esfera doméstica - no cuidado com a casa, limpeza, preparo dos alimentos e, também, no cuidado com os filhos - em particular entre as famílias das classes média e alta. A recente regulamentação do trabalho doméstico por meio da Lei Complementar n.150/2015, que torna o processo de contratação e manutenção de empregados domésticos mais dispendioso na medida em que estabeleceu o pagamento de encargos antes inexistentes para os patrões (como Fundo de Garantia por tempo de Serviço, pagamento de Horas Extras, entre outras mudanças) pode vir a ser um fator que vem agravar o descompasso entre a divisão das tarefas domésticas e o trabalho entre os casais, principalmente os de classe média.

Quanto ao papel das empresas nessa nova realidade em que o casal trabalha em tempo integral, torna-se necessária a criação de políticas que atendam aos pais e às mães que desempenham essa dupla função - trabalho no mercado profissional e dentro de casa, cuidando e criando os seus filhos e realizando as tarefas domésticas. No entanto, conforme abordado no referencial teórico, a maioria das empresas brasileiras não se adaptou às demandas familiares dos seus funcionários. Tais estratégias de harmonização entre o trabalho e a vida familiar, de acordo com o que já foi sinalizado, têm obtido resultados satisfatórios em alguns países desenvolvidos.

No Brasil, contudo, face ao crescimento do percentual de desempregados e do enfraquecimento estrutural do movimento sindical, as possibilidades de criação de políticas nas organizações que permitam uma adaptação das demandas destas às necessidades de pais e mães são cada vez mais reduzidas. O medo do desemprego e a diminuição do poder de barganha dos sindicatos acabam impondo às pautas de negociação temas mais emergenciais para a classe trabalhadora, que não incluem a criação de políticas que contemplem uma redução de jornada para pais e mães com filhos, ou mesmo uma maior tolerância, por parte das empresas, com as ausências dos funcionários para atender às demandas escolares ou médicas dos filhos. Ao que parece, estas questões permanecerão restritas à esfera privada das famílias, dependentes de soluções individuais, e não sendo encaradas como um problema social que merece ser debatido entre famílias, empresas e governos.

Neste sentido, não se pretendeu, aqui, esgotar um tema tão abrangente, muito menos formular conclusões gerais a respeito. Pretende-se, tão somente, lançar algumas pistas a serem aprofundadas em estudos posteriores. Para tanto, recomenda-se a realização de pesquisas de campo que busquem traçar um panorama sobre este processo entre casais de dupla jornada no Brasil, e como se dá esta organização no âmbito das famílias. Outro aspecto que merece um maior aprofundamento se refere ao trabalho de babás e empregadas domésticas as quais, por sua vez, também estão reféns das mesmas demandas que seus patrões, pois acabam estendendo sua jornada de trabalho para atender às jornadas estendidas das famílias para as quais trabalham. Outra consequência direta deste fenômeno, e que também merece ser estudada, é o impacto sobre os filhos, posto que é possível entender esta questão como um problema que deve ser enfrentado no âmbito das políticas públicas para a infância. 


\section{REFERÊNCIAS}

BANDEIRA, E. L. et al. O conflito trabalho-família vivenciado por mulheres empreendedoras do setor de confecção. In: Encontro de Gestão de Pessoas e Relações de Trabalho, 6., 2017. Curitiba. Anais... Curitiba: ANPAD, 2017.

BONELLI, M. G. Arlie Russell Hochschild e a sociologia das emoções. Cadernos Pagu, v. 21. p. 357-372, 2003.

CHAMPALBERT, L. La Organización de la vida doméstica según ellas y ellos. In: LÓPEZ, E.; FINDLING, L. (Coord.). Maternidades, paternidades, trabajo $\mathbf{y}$ salud. Transformaciones o retoques? Buenos Aires: Biblos editorial, 2012.

CRAMER, L. et al. Representações femininas da ação empreendedora: uma análise da trajetória das mulheres no mundo dos negócios. Revista de Empreendedorismo e Gestão de Pequenas Empresas, v. 1, n. 1, p. 53-71, jan/abr. 2012.

DANIEL, C. O Trabalho e a questão de gênero: a participação de mulheres na dinâmica do trabalho. O Social em Questão, ano XIV, n. 25/26, p.323-344, 2011.

DINIZ, G. Homens e mulheres frente à interação casamento-trabalho: aspectos da realidade brasileira. In: FÉRES-CARNEIRO, T. (Org.). Casal e família: entre a tradição e a transformação. Rio de Janeiro: NAU, 1999. p. 31-54.

FLECK, A. C.; WAGNER, A. A mulher como a principal provedora do sustento econômico familiar. Psicologia em Estudo, v. 8, num. esp., p. 31-38, 2003.

GAREY, A. I. Maternally yours: the emotion work of "maternal visibility". In: GAREY, A. I.; HANSEN, K. V. (Edited). At the heart of work and family. Enganging the ideas of Arlie Hochschild. United States of America: Rutgers University Press, 2011.

HANSEN, K. V. The asking rules of reciprocity. In: GAREY, A. I.; HANSEN, K. V. (Edited). At the heart of work and family. Enganging the ideas of Arlie Hochschild. United States of America: Rutgers University Press, 2011.

HOCHSCHILD, A. R. The time bind. when work becomes home and home becomes work. United States of America: Henry Holt and Company, 1997.

HOCHSCHILD, A. R. "Rent a mom" and other services: markets, meanings and emotions. Sociology Department, University of California, 2005.

HOCHSCHILD, A. R. The second shift. working families and revolution at home. United States of America: Penguin Books. 2012a.

HOCHSCHILD, A. R. The outsourced self. What happens when we pay others to live our lives for us. New York: Picador, $2012 \mathrm{~b}$. 
IBGE/INSTITUTO BRASILEIRO DE GEOGRAFIA E ESTATÍSTICA. Pesquisa Mensal de $\begin{array}{lllll}\text { Emprego } & - & \text { PME. } & 2012 . & \text { Disponível }\end{array}$ https://www.ibge.gov.br/home/estatistica/indicadores/trabalhoerendimento/pme_nova/Mulher _Mercado_Trabalho_Perg_Resp_2012.pdf. Acesso em: 13 fev. 2017.

LEHNER, M. P. La valoración del trabajo. In: LÓPEZ, E.; FINDLING, L. (Coord.). Maternidades, paternidades, trabajo y salud. Transformaciones o retoques? Buenos Aires: Biblos editorial, 2012.

LOUREIRO, C. M. P.; COSTA, I. S. A; FREITAS, J. A. S. B. Trajetórias profissionais de mulheres executivas. Revista Ciências da Administração, v. 14, n. 33, p. 130-144, ago. 2012.

MADALOZZO, R.; MARTINS, S. R.; SHIRATORI, L. Participação no mercado de trabalho e no trabalho doméstico: homens e mulheres têm condições iguais? Revista Estudos Feministas, v. 18, n. 2, p. 547-566, maio/ago. 2010.

MENEZES, T. O retrato da nova família. 2012. Disponível em: https://istoe.com.br/247220_O+RETRATO+DA+NOVA+FAMILIA/ Acesso em: 13 jul. 2017.

NASCIMENTO, A. C. H. Z. Concepção de maternidade para mulheres executivas: uma questão contemporânea. In: Encontro de Gestão de Pessoas e Relações de Trabalho, 6., 2017. Curitiba. Anais... Curitiba: ANPAD, 2017.

NEVES, D. R. Bases do contrato psicológico de profissionais atuantes em empresas de alta performance. 2013. Dissertação (Mestrado) - Programa de Pós-Graduação em Administração de Empresas, Pontifícia Universidade Católica do Rio de Janeiro, Rio de Janeiro, 2013.

OLIVEIRA, N. H. D. Recomeçar: família, filhos e desafios [online]. São Paulo: UNESP; Cultura Acadêmica, 2009. 236 p. Disponível em: <http://books.scielo.org>. Acesso em: 13 jul. 2017.

PERLIN, G.; DINIZ, G. Casais que trabalham e são felizes: mito ou realidade. Psicol. Clin. [online], v. 17, n. 2, p. 15-29. 2005.

ROCHA-COUTINHO, M. L. Novas opções, antigos dilemas: mulher, família, carreira e relacionamento no Brasil. Temas em Psicologia da SBP, v. 12, n. 1, p. 2-17. 2004.

SANTOS, H. B. O processo de dual career family: um estudo sobre os impactos e implicações na vida do casal. 2011. Tese (Doutorado) - Departamento de Administração da Faculdade de Economia, Administração e Contabilidade, Universidade de São Paulo, São Paulo, 2011.

H. B. O processo de dual career family sob a ótica brasileira: desvendando tipologias. In: Encontro da ANPAD, 36., 2012. Rio de Janeiro. Anais... Rio de Janeiro: ANPAD, 2012. 
H. B. Casa e carreira: qual o preço da escolha? um estudo sobre os prós e contras na relação do casal contemporâneo brasileiro. In: Encontro da ANPAD, 37., 2013. Rio de Janeiro. Anais... Rio de Janeiro: ANPAD, 2013.

H. B. The Dual career process in the brazilian perspective: unraveling typologies. Revista de Administração, v. 50, n. 4, p. 507-522, 2015.

SANTOS, H. B.; CASADO, T. O fenômeno dual career: um estudo sobre suas características em casais brasileiros. In: Encontro de Gestão de Pessoas e Relações de Trabalho, 3., 2011. Paraíba. Anais... Paraíba: ANPAD, 2011a.

O tradicional reconfigurado: a proposta de um modelo para casais de dupla carreira. In: Encontro da ANPAD, 35., 2011. Rio de Janeiro. Anais... Rio de Janeiro: ANPAD, 2011b.

SMITH, V. Shift work in multiple time zones: some implications of contingent and nonstandard. In: GAREY, A. I.; HANSEN, K. V. (Edited). At the heart of work and family. Enganging the ideas of Arlie Hochschild. United States of America: Rutgers University Press, 2011.

SOUZA, A. B. L.; BELEZA, M. C. M.; ANDRADE, R. F. C. Novos arranjos familiares e os desafios ao direito de família: uma leitura a partir do tribunal de justiça do Amazonas. Revista Eletrônica de Humanidades do Curso de Ciências Sociais da UNIFAP, n. 5, p. 105-119, dez. 2012.

VENTURIELLO, M. P. El cuidado de los hijos: dominios femeninos-dominios masculinos. In: LÓPEZ, E.; FINDLING, L. (Coord.). Maternidades, paternidades, trabajo y salud. transformaciones o retoques? Buenos Aires: Biblos editorial, 2012.

VILELA, N. G. S.; LOURENÇO, M. L. Políticas organizacionais e governamentais e o conflito trabalho-família em diferentes países: um estudo bibliográfico. In: Encontro de Gestão de Pessoas e Relações de Trabalho, 6., 2017. Curitiba. Anais... Curitiba: ANPAD, 2017. 